\title{
The triple oxygen isotope composition of carbonatites
}

\author{
${ }^{1}$ Benjamin R. Fosu, ${ }^{1,2}$ Prosenjit Ghosh, ${ }^{3}$ Tobias \\ B.WEISENBERGER, ${ }^{4}$ SimON SPÜRGIN, ${ }^{5,6}$ Shrinivas G. \\ VILADKAR \\ ${ }^{11}$ Centre for Earth Sciences, Indian Institute of Science, \\ Bangalore 560012, India (benjaminf@iisc.ac.in) \\ ${ }^{2}$ Divecha Centre for Climate Change, Indian Institute of \\ Science, Bangalore 560012, India (pghosh@iisc.ac.in) \\ ${ }^{3}$ Iceland GeoSurvey (ÍSOR), Rezkjavik, Iceland \\ (tobias.weisenberger@t-online.de) \\ ${ }^{4}$ Hans G. Hauri KG Mineralstoffwerke, Bötzingen, Germany \\ (s.spuergin@hauri.de) \\ ${ }^{5}$ Carbonatite Research Centre, Amba Dongar, Kadipani \\ 390117, India (sviladkar@gmail.com) \\ ${ }^{6}$ Department of Earth and Environmental Sciences, IISER \\ Bhopal, Bhopal 462066, India
}

We present triple oxygen isotope data of carbonates in carbonatites sampled from different localities worldwide in order to assess mass-dependent fractionation during the formation of mantle rocks. We consider the mineralogical differences in the mantle-derived carbonatites in our evaluation and constrain further the triple oxygen isotopic composition of the mantle. The analytical approach follows the acid digestion of sample carbonates to release $\mathrm{CO}_{2}$ that is further processed through catalytic exchange with $\mathrm{O}_{2}$. Through robust standardisation and calibration routines, the triple oxygen isotope composition $\left(\Delta^{17} \mathrm{O}\right)$ of the carbonate is derived from the processed $\mathrm{CO}_{2}$. Our results show that $\Delta^{117} \mathrm{O}$ signatures of calcite and dolomite carbonatites are independent of mineralogy, suggesting the compositional variation $(0.005 \%)$ and isotopic fractionation associated with the different carbonate phases, at magmatic temperatures is negligible. The determined average $\Delta^{177} \mathrm{O}$ composition of the carbonatites, assumed to reflect that of the mantle is -0.052 $\pm 0.006 \%$ (vs. VSMOW; $\lambda=0.528, \mathrm{n}=25$ ), indicating the mantle has a relatively homogenous isotopic composition. Ferrocarbonatites and lapilli tuffs have distinctively low $\Delta^{17} \mathrm{O}$ values $\left(-0.160\right.$ to $-0.106 \%$ ) consistent with their high $\delta^{18} \mathrm{O}$ and clumped-isotope $\left(\Delta_{47}\right)$ signatures. These results suggest diagenetic reactions facilitated by low-temperature fluid-rock interaction, and the mixing of carbonate sources induce alterations in primary mantle signatures that are detectable in both triple oxygen and clumped isotope compositions of the rocks. 